\title{
Book Review: O’Loughlin, M., \& Johnson, R. (Eds.),(2010). Imagining Children Otherwise: Theoretical and Critical Perspectives on Childhood Subjectivity
}

\author{
Robin Adeney, University of Regina \\ Kimberly Bezaire, University of Toronto \\ Jane Hewes, Grant MacEwan University \\ Patrick Lewis and James McNinch, University of Regina
}

\begin{abstract}
A book review of O’Loughlin, M., \& Johnson, R. (Eds.), (2010). Imagining children otherwise: Theoretical and critical perspectives on childhood subjectivity. New York: Peter Lang Publishing.
\end{abstract}




\section{Book Review: O’Loughlin, M., \& Johnson, R. (Eds.),(2010). Imagining Children Otherwise: Theoretical and Critical Perspectives on Childhood Subjectivity}

This inspiring anthology encourages us to imagine childhood and education outside of the commonplace and predictable frames that culture and place has constructed. The authors approach the subject from various perspectives as the reader is cajoled to look beyond the borders and edges of fixed developmental and linear trajectories in children's lives and to unleash our subjectivities. The reading is complex, perplexing and often disturbing in its message. We are urged to imagine children otherwise.

Theory should help us to see things in the real world in new ways and to make meaningful connections to our own experience, and this book does not disappoint. The reader is delighted by the possibilities that it offers for deepening the pedagogical discourse around children as citizens and the agency of the child introduced in The UN Convention on the Rights of the Child, ${ }^{1}$ as well as on the image of the child as the basis of authentic pedagogical relations, revealed in the educational philosophy of Loris Malaguzzi and the educators of Reggio Emilia. ${ }^{2}$

The notion of childhood subjectivity explored in this book not only adds another thoughtprovoking dimension to these already rich, multidimensional concepts, but compels us to consider the practical implications for our pedagogical relations with children and young people. The connections between the theoretical arguments and everyday life are inscribed in story in these chapters-and the implications are much more tangible as a result. Importantly, these chapters offer starting points for talking meaningfully with others about ideas not often consider seriously-like ghosts-and engaging productively and thoughtfully with others about uncomfortable issues, especially those that make us feel helpless-like our collective responsibility to children and youth, including those within the social service system and young offenders.

\section{Chapter 1: Reading, Writing, and the Wrath of My Father Author: Jonathan G. Silin}

Silin begins his chapter by reminding readers of the taken for granted legacy of NCLB in the form of the oppressive standards and accountability movements filtering their way into early childhood settings. Every activity, movement, and story is orchestrated and scripted to ensure that some learning outcome, a narrow notion of literacy in particular, is attacked then measured in order to rate a child's success or failure. An efficient form of "literacy takes precedence over life” (p. 14).

However, very quickly drawing on the power of story, he takes the reader through an autobiographical journey of his own literacy learning remembered, what Grumet and Pinar (1976) once called currere (the course ran) in the early days of the curriculum reconceptualists. "One returns to the past, to capture it as it was, and as it hovers over the present" (p. 55). Through a rereading of his text and the text of school and society written across and at crosspurposes to his own lived story, Silin re-narrates the curricular self, past and present, through a recursive story of learning and loss. But his loss seems more to be about his own "sense of being lost” (p. 20) and the similar sense of being lost that many children experience when trying to negotiate the strangeness of school in the early years and the sudden imposition of the importance of literacy learning when oracy skills work just fine. Entwined with his school journey and literacy life are the story of understanding his sexuality and the concomitant desires, joys, and pains. In his pedagogical realization, "learning may bring with it a loss of connection to 
people and ways of being that feel good and right." Consequently, teachers and schools need to create places and spaces "for pleasure, for reading and writing texts that speak to and from the body about things that really matter to teachers and students, including sexuality” (p. 25). For what are schools and the curriculum? The curriculum, Madeleine Grumet (1981) said, is "the collective story we tell our children about our past, our present, and our future” (p. 115). What are the stories we are telling in school today?

\section{Chapter 2:Ma Wai He Kapu Ti?: Being, Knowing, and Doing Otherwise in Early Childhood Education in Aotearoa Author: Jenny Ritchie}

The essay by Jenny Ritchie transports us to Aotearoa/New Zealand and stories of how British colonizers de-valued the knowledges and languages of the indigenous Maori. Despite the successful development of a curriculum that adopts these practices (Te Whariki, Ministry of Education, 1996), there remains a privileging of colonizer culture. Jenny Ritchie, a Pakeha, advocates for an education that values Maori traditional ways of knowing and being. She suggests that it is at the micro-level, the relationship level, of interactions between teachers, children, and families that latent "historical subjectivities" can be made known. Simple traditions such as greeting a parent with a cup of tea, a Maori way of being, can be an instrument of transformation. Respect and connection with the land and sea, integral to Maori identity, is another way that educators can authentically value indigenous ways. The author states that courage is needed by educators to push post-colonial boundaries and not carry colonialist baggage. The message is one of hope as Ritchie concludes that educators are committed to transforming their practices and to re-validating Maori subjectivities.

\section{Chapter 3: Ghostly Presences in Children's Live: Towards a Psychoanalysis of the Social Author: Michael O'Loughlin}

O’Loughlin makes a convincing case for the existence and influence of ghosts in the development of children's subjectivity. His argument is a simple one-we all carry with us the stories of our families, passed down to us through the generations, mostly in unconscious and disembodied ways. These stories - those that are spoken as well as those unspoken and in some cases, unspeakable stories - can profoundly influence how children begin to tell their own story and build a sense of subjectivity and identity. The past is present in children's lives. O'Loughlin argues that if we can give language to these spectral presences, if we tell these stories out loud, they can become part of our subjectivity; if they are left unspoken, they act to subject rather than subjectify. I was delighted by his reference to Vivian Paley's work on the importance of fantasy play as a natural context in which children can give language to this kind of unconscious and intuitive knowledge, by themselves and for themselves.

The chapter is grounded in a critical and reflective consideration of the psychoanalytic literature on the development of subjectivity and by O'Loughlin's recent book The Subject of Childhood. ${ }^{3}$ O'Loughlin argues that the dehistoricized nature of traditional theories of subjectivity renders them inadequate to explain or to support the unfolding of subjectivity and multiple identities increasingly characteristic of a diverse society. He weaves together seemingly disparate theoretical constructs in a tantalizingly poetic way-walking the reader through the "psychoanalysis of the social," and the "archeology of anguish," mingled with real life stories of "hungry ghosts" at work in the life of a descendant of the Irish famine. Along the way we are 
reminded of children's intuitive ways of being, of their openness to the liminal world, and of the connections between identity, spirituality, and learning.

The most powerful part of the chapter comes at the end, when O'Loughlin invites us to consider the possibility of a "liveable pedagogy," an "evocative pedagogy" and a "regenerative curriculum." This is a pedagogy that "speaks to the unconscious" (p. 69), one that aims to create "spaces where diverse identities can be imagined, inscribed and invented" (p. 57). He concludes that educators must listen to the "ghostly echoes" in children's lives, in particular to those children whose families have suffered the trauma of "war, displacements, genocides, annihilations of religious and cultural values, and the systemic erasure of ancestral memory and language” (p. 70). Psychoanalysis meets pedagogy; albeit a challenging read, it is immensely satisfying.

\section{Chapter 4: Alice Down the Rabbit Hole and Through the Looking Glass Author: Karen Lombardi}

Karen Lombardi offers a narrative and autobiographical psychoanalysis of a child's early inner life. She extends a compelling image of the young child as personally aware and capable of struggling with psychic and philosophical paradox-infinity, mortality, self and otherness. Beginning with a review of literature regarding the inner life of infants-readers consider children's active experiences of loss, mourning, emotional connection to significant others, security, and sense of self. Lombardi then takes us deeper, exploring the roots of subjectivity and culture within the dynamics of parental relationship, and phantasy. Finding connection and inspiration in the wordplay of Lewis Carroll's Alice in Wonderland, while viewing childhood experience through the theories of Klein and Kristeva, the author explores childhood capacities in "the struggle to live lovingly through terrible similarities and unbreachable differences" (p. 79). Lombardi pushes the boundaries of psychoanalytic theory, clinical analysis, and personal reflection, presenting possibilities for childhood identity construction-exploring dreams that are at turns funny, frightening, exciting - always engaging, thoughtful and challenging.

\section{Chapter 5: New Zealand-Based Samoan Youth Offenders: Working the Spaces Between Author: Tamasailau M.Suaalii-Sauni}

In the introduction to the book, Michael O’Loughlin says that Chapter 5 will "set your teeth on edge" —an apt description. Almost immediately, I found myself reading recent media coverage of youth gang violence with an entirely new perspective. The chapter opens with a poem about Ese, a Samoan youth offender, which sets the stage for Suaalii-Sauni to explore the "competing scripts" and conflicting expectations of Samoan youth offenders "as young people of an ethnic minority group branded deviant” (p. 89). This chapter brings readers the voices and stories of the Samoan youth offenders themselves. Suaalii-Sauni is quick to confess that "in many ways it is also my story about us, about our failures to hear their stories, to see their lives, and to give them help" (p. 89). She challenges us to imagine these children otherwise, and to support them in seeing other possibilities for themselves and choices for action that are not only more consistent with accepted social behaviours, but also choices that are consistent with their own stories about themselves. Her analysis and writing is deeply thoughtful. She includes a quote attributed to Charles Dickens, reminiscent of O'Loughlin's discussion of the influence of ghostly presences, which describes the "forces that affect our lives" as "whispers in a distant room, teasingly indistinct, apprehended only with difficulty” (p. 103). 
One of the most enticing dimensions of this chapter and others chapters is that they take us beyond the image of a wounded child in search of a child with a sense of agency, or as O'Loughlin describes it "the kernel of interiority" (p. 69). When we allow schools to be places where "children work in freeing spaces that facilitate emotional expression" (p. 68) and where education is not "structured so that it is exclusively about curriculum imperatives and behavioral expectations” (p. 68)—schools can become places where children can integrate and normalize the influence of traumatic events in their own lives, where they can write their own story, developing an identity based on a sense of personal agency.

\section{Chapter 6: Putting Myself in the Picture: Oppositional Looks as Sites of Resistance Author: Richard Johnson}

The contribution of this volume's co-editor, Richard Johnson, is a curious piece. It begins with a picture of a toilet and an anecdote about the problematic issue of toilet-training in kindergarten and the reluctance of school systems to allow anyone but the parent to deal with children who soil themselves. This triggers an exploration of several photographs (reproduced in the text) of the author as a young man engaged in child care, and of other objects, notably a rocking chair signifying the embodied soothing involved in comforting a child. Johnson's method is to use visual culture to stimulate narrative and self-study and let "images speak to a dominant discourse in education” (p. 117). Drawing on the work of Beth Tobin and inspired by Mary Douglas and J. Kristeva, Johnson's purported goal is to "destabilize and dismantle normative imperialist legacies in early childhood education” (p. 118). From there the essay reads like an attempt to embed Johnson's own stance into critical theory as if needing to prove that early childhood and early childhood education is worthy of such an exploration as well as to prove that he is capable of positioning himself on the issue of subjectivity through "personalized phototherapy" (p. 120). What the essay lacks is any deep discussion of the feelings and ideas raised by this process of "'putting himself into the picture." The fears and taboos surrounding potty-training remind Johnson of how both child and caregiver have become "abject," "disembodied," "contested," and "altered." His memories of the past are how his "natural” body "willingly and graciously provided warm, consoling and deliberate caring touch(es) and compassion to those in my charge" (p. 126). Now he feels more like a stranger, an intruder, and "I am dumbfounded by my new found foreign stature." I (McNinch) am led to speculate that Johnson's insistence on connecting the dots between dozens of theorists might well explain this deep disassociation and alienation. I read this chapter just before meeting a 14-year-old boy, Beau, who is neurologically and physically damaged through fetal alcohol spectrum disorder. He didn't walk until he was 5 . No one can understand what he is saying. His grandmother tells me that he is not toilet-trained and I wonder how Beau is going to fare at his new school. I also wonder if some strong and consistent behavior modification techniques and rewards might have helped Beau to take control of his voice and his bowels. It is clear to me that he has not been cared for adequately. Both Beau and Johnson's chapter left me, too, feeling abject and alienated.

\section{Chapter 7: Working and Reworking Children's Performances of 'Whiteness' in Early Childhood Education}

\section{Authors: Glenda MacNaughton, Karina Davis, \& Kylie Smith}

The authors in this chapter call upon readers to recognize how discourses of privilege and racism may be performed by our youngest citizens, and call on readers to find strategies and new pedagogies for challenging children's racialized views of "whiteness" as normalized and desirable. The authors bring readers beyond and outside of traditional discourses of 
developmental psychology, which would position and possibly normalize children's racial prejudice within developmental steps and stages. Rather these researchers employ varied critical, creative methods for viewing children's racial awareness within the context of societal, historical, racial politics in $21^{\text {st }}$ century Australia.

It is both uncomfortable and thrilling to experience the lines of flight created in this thoughtful, critical analysis of children's performance of whiteness, examining how 4-year-old participants negotiate and construct/perform racialized identities in the context of semi-structured interviews during doll play. Disrupting images of the child as belonging to a time and social place apart, this work strips away romantic notions we may hold of childhood as a time of innocence, as children articulate their understanding of race and "the desirability of whiteness" in personal, meaningful ways (p. 138). Employing a range of methods in discourse analysisnamely, rhizoanalysis, cartography, and decalcomania-the researchers strive to "make transparent", "rupture” and "disrupt" dominant discourses, from a Foucaultian perspective. Perhaps most provocatively, the authors privilege children's voices-explicitly and articulately portraying their child participants as "powerful agentic subjects" who are involved in political and social discourses that "produce and reproduce the violence of 'whiteness"” (p. 137). The authors most effectively disrupt our image of child study by juxtaposing the voices/perspectives of four Australian women authors-women who write powerfully about racism from outside the field of early childhood-with the voices of child participants, as these young children position themselves within views of white as normal and desirable. In doing so, we are placed in new sites from which to view childhood subjectivities, racial politics and dominant assumptions, squarely faced with the challenge to recognize and reimagine our teaching practices.

\section{Chapter 8: Subjectivity Unbound: Escaping the 'Mortal Engines' of the West Author: Derek Bunyard}

Derek Bunyard's challenging and thought-provoking essay, "Subjectivity Unbound," explores the historical roots of the current state of education and its links with the Industrial Revolution and assembly line work. The author outlines how the structure of our modern schools was partly created by theorists such as Darwin, mind and body connection; Watson, behaviorism; Piaget, developmentalism; and Thorndike, operant conditioning, among others. He describes how these thinkers directed us to a path of controlled and programmed learning in schools that was well entrenched in classrooms by the 1950s and the era of Sputnik. Education was wed to the military industrial complex in a fixed developmental trajectory. The consequence of this was that the individualism of the learner was marginalized and schools evolved to be predominantly static, closed, and conforming places. The essay ends by reminding us of the instability of our subjectivities and the goal of somehow connecting children to lives of consciousness, free choice, and voice beyond the confines of conventional classrooms.

\section{Chapter 9: Who Let the Dogs Out?: Unleashing an Uncanny Sense of Audience in the Writing Workshop Authors: Paula M. Salvio \& Gail Boldt}

Salvio and Boldt (2010) begin unpacking their playful chapter title through two examples of students' (6 and 9 years of age) textual confluence of ideas and experiences in a writing activity; one from the mid 1980s documented by Anne Martin (1989) and the other more recently. Pointing out the lack of logic or adherence to the conventions of writing a story that the two pieces demonstrate, the authors suggest the writings are examples of the children's 
pleasurable exploration of text, the unconscious/conscious purposes (private or social) that inspired the children to write the pieces (p. 180).

Salvio and Boldt then provide a brief albeit clear description of the evolution both politically and practically of the writing process over the past 30 plus years and the significant changes in principles, practice, and philosophy since the early days of D.W. Graves and others as teaching has moved to Teaching and process has been eclipsed by product.

Conflating the works of James Britton, Clare Winnicott, and D.W. Winnicott the authors make a compelling case for the recognition "that psychoanalysis gives us a frame for examining issues often overlooked by socio-cultural theories of writing” (p. 183).

Furthermore, they argue that "we must understand the unconscious as always a potential player in any expressions of meaning” (p. 183), including and especially writing. The authors travel across the landscape of ideas born out of the work of the Winnicotts and Britton and how today's writing workshop, epitomized in the programs and ideas articulated by Lucy Calkin and Nancie Atwell and others, have replaced those earlier rich and engaging writing activities for children and youth. Those earlier processes and practices "have been displaced by pedagogical practices being marketed by 'audit culture'”' (p. 184).

Drawing on the Winnicotts' and Britton's notions of play, Salvio and Boldt remind us of the importance of play in the life of the child and that it is play and playfulness which are integral to a child's navigation and understanding of the adult literate world. The absence of play in current teaching practices, not just in the form of play time, but rather the playfulness of language, playing with language, and the play of language are nowhere to be found in current literacy teaching practices throughout most of North America. As the authors note, teachers and students are overwhelmed by behaviourist scripted programs like Lucy Calkin's that cloak themselves in the language legacy of process writing (i.e. Graves and Britton), but in fact have a dearth of the most important aspects of literacy learning, time and play. Lev Vygotsky (1933, as cited in El'konin, 2005) wrote, "before play there is no imagination" (p.14). As the authors suggest of Britton and Winnicott, we too should "be sickened by the exclusion of play and fantasy from the current writing curriculum” (p. 201). Teachers and teacher educators need to remind themselves of the importance of play in all facets of learning and teaching; play across the curriculum and praxis.

\section{Chapter 10: The Curious Subject of the Child Author: Michael O’Louglin}

The last chapter of this anthology is the contribution of co-editor, Michael O'Loughlin. Like Johnson, he begins by looking at photographs; in this instance from his first communion and confirmation into the Irish Catholic Church. What follows is some close memory work of his own family and school experiences as a bright rural working class boy in a school system designed for the children of the urban middle class. O'Loughlin's essay explores "the powerful pull of my past and causes me to search for a nuanced understanding of what constitutes my coming to be in the world” (p. 208). Like Johnson, there are many references to theorists, including Barthes, Lacan, Foucault, and Butler, but O’Loughlin has a deft hand integrating his memories and observations within theoretical structures. As a psychoanalyst, he is concerned with uncovering trauma and looking for symptoms and signs of such trauma "disguised in the language of everyday life” (p. 216). Quoting Anthony Clare, a psychiatrist, O’Loughlin queries the violence at the root of child-rearing practices in Ireland, both in the home and in the school. 
This has led to the national psychosis that is Ireland: "A culture heavily impregnated by an emphasis on physical control, original sin, cultural inferiority and psychological defensiveness." The chapter ends with an invitation from the author to the reader "to engage in dialogue around the expansive possibilities of subjectivity" (p. 223). Childhood is a space we continue to inhabit the older we get. The drunken rage and sometimes violence of my own Irish father, directed against my mother and us three children is certainly part of my own subjectivity (McNinch). But that's another story for another time.

\section{Closing}

The idea of imagining children otherwise is a call to action. In order to understand children as citizens, we must be able to imagine them in completely new ways. But our first calling, as educators and family and community, is to help children to imagine themselves otherwise, to tell their own story. As O'Loughlin and the other authors illustrate, this act of imagining the child otherwise is not always easy or comfortable. We must be prepared to listen carefully to "the identities...they take on and those imposed” (p.89). It is the essence of our work as educators to open up possibilities, to make possible futures visible, to recognize possible identities. But we must also be mindful of the possibilities children and young people do and don't see for themselves; and in some cases of the stark contrast between possibilities and opportunities. One is left wondering about what happens in communities where beside every young person haunted by the ghosts of generations of unspeakable trauma and violence there is another child and another and another, wrestling with similar personal and social histories. We simply must find a way to imagine these children otherwise. 


\section{References}

El'konin, D.B. (2005). The psychology of play. Journal of Russian and East European Psychology, 43(1), 11-97.

Grumet, M. (1981). Restitution and reconstruction of educational experience: An autobiographical method for curriculum theory. In M. Lawn \& L. Barton (Eds.), Rethinking curriculum studies: A radical approach (pp. 115-130). London: Croom Helm.

Pinar, W., \& Grumet, M. (1976). Toward a poor curriculum. Kendall/Hunt Pub. Co.

\section{Endnotes}

${ }^{1}$ United Nations. (1991). Convention on the rights of the child (1989). New York: United Nations.

${ }^{2}$ Edwards, C.P., Gandini, L. \& Forman, G. (1993). The hundred languages of children: The Reggio Emilia approach to early childhood education. Norwood, NJ: Ablex Publishing.

${ }^{3}$ O’Loughlin, M. (2009). The subject of childhood. New York: Peter Lang Publishing. 